\title{
Notes on design education and (prefigurative) work politics
}

\section{Brave New Alps}

Bianca Elzenbaumer, Leeds College of Art

Fabio Franz, Sheffield School of Architecture

\begin{abstract}
In this text we are reporting back on the practice-based research Precarity Pilot. The starting point for this research is the fact that in today's Europe, design graduates are entering into a landscape of precarious work. This research-inprogress thus enquires into how formal and informal design education can be a space where to empower young designers to transformatively engage with the precarious work politics of their profession. As a mid-way result, here we present a series of didactic proposals and strategic questions for how issues of socioeconomic precariousness can be transformatively addressed. This result is based on a series of half-day workshops we have been running between 2014 and 2016 with design students, recent graduates and design educators in the United Kingdom, Germany, Poland and Italy. We address these proposals to educators, managers and students alike as we are convinced that everyone involved in education has agency over how the learning process unfolds.
\end{abstract}

\section{Keywords}

precariousness

work 
diversity

economies

collective action

didactic proposals 
If we work, where we work, with whom we work, what we do at work, and how long we work are social arrangements and hence properly political decisions, how might more of this territory be reclaimed as viable terrain of debate and struggle? (The Problem with Work, Kathi Weeks)

In today's Europe, design graduates are entering into a landscape of precarious work (Berardi 2009; Lorey 2011; Standing 2011). Bulimic work patterns, low pay, work in isolation, work-related health problems, and work taking over life are all the order of the day and they come coupled with all the symptoms of a downsized welfare systems, such as no paid vacations, no sick leave, no unemployment compensation, no parental leave, no pension provision (Elzenbaumer 2014; Raunig et al. 2011; McRobbie 2015). And while not all these elements of precariousness are present all the time for everyone, different combinations of them traverse the life of most workers in Europe - not just designers. Moreover, the neo-liberal work culture that has been rolled out through neo-liberal politics since the 1970s, implies that no matter how successful you are today, you are only always as good as your last project. This means that both failure and success are always just around the corner and the pressure to compete with others in order to sustain oneself is a constant companion in today's world.

Despite the ubiquity of these conditions, which contribute to shape not only people's design practice but also their lives, they are rarely discussed within design education and students are often left in a bubble of cruel optimism (Berlant 2011) that pictures the work of designers as a big playground where you will 'do 
well' if only you are creative enough and work hard enough. However, this bubble is abruptly undone for many upon graduation. As the detailed anonymous survey 'Designers' inquiry' (Cantiere per pratiche non-affermative 2013) showed, only on entering the world of work do many graduates realize that much of their profession is systemically ridden by an unsatisfying ratio between working hours and pay, a tendency to work in isolation and the necessity to still be supported by a family network because the generated income does not allow for economic independence (Elzenbaumer and Giuliani 2014). Given this situation, which is problematic especially for people from a less privileged socio-economic background, it is important for design schools to address the systemic conditions of precarious work in order to undo the false impression that precariousness equals personal failure and that one should deal with it by oneself.

We are convinced that precarious work raises questions and issues that need to be addressed collectively and that design education can be a space to empower designers to transformatively engage with the work politics of their profession. So what we present in what follows, is a mixture of didactic proposals and strategic questions that we hope can support young designers in unravelling the precarizing economies and relational dynamics of their profession, while also galvanizing ideas of how to collectively do something about them.

The proposals and questions we present here have developed out of a series of workshops we have been running between 2014 and 2016 with design students, recent graduates and design educators in the United Kingdom, Germany, Poland and Italy as part of our research project Precarity Pilot (n.d.). The three-hour-long 
workshops were thematically focused on a range of issues pertaining to precarious design work such as the transition from university to work, the tools of the trade, the re-shaping of role models and ideas for collective support structures. They involved between 6 to1 8 people per session. Some of the workshops were one-off engagements, while others where organized as a series. According to the context in which the workshops took place - either in settings of self-organized learning, within cultural institutions or higher education - they were either composed of designers and other cultural producers (such as architects, artists and curators) at different stages of their working lives or by a more homogenous group of people studying on one specific design course. As the workshops unfolded, similar issues kept cropping up across the different contexts (such as the exclusivity of the field, the unintelligibility of the economies of certain design practices, the struggle with internships, the confusion about the tools of the design trade) and here we try to address them by pulling them together into thematic strands. For some of these strands, we allow ourselves to advance didactic proposals of how they could be addressed, while for others we can only currently lay out questions which we hope will stimulate the didactic creativity of others.

\section{Didactic proposals and strategic questions}

\section{Asking guest speakers to unravel the economies of their practice}

Guest lectures by practicing designers - at whatever stage of their working lives - are a great inspiration to students and tutors alike. However, these lectures are often limited to showcasing final project outcomes without introducing the audience to what is going on (economically) behind the scenes 
of a certain practice. To make sure such occasions become a richer learning experience, we invite you to experiment with asking your guest speakers to address some of the following questions: Can you map your sources of income? What does one financial year look like in your practice? What free or affordable resources can you rely on? What kind of unpaid work/contributions can you count on? How do you access work? How do you negotiate the exchanges a project entails? What is your work-life balance? What does your working week look like? If you have kids, how do you reconcile work and care? What strategies of organization and exchange do you use to keep your practice going?

\section{Diversifying references and role models}

The design profession is predominantly made up of white male designers (de Bondt and van den Berg 2012; Montgomery 2016; Rawsthorn 2011) and much of the focus of the design press is on practices located in western metropolitan cities. This composition does however not reflect the composition of the student body, which tends to be much more diverse and in many places predominantly female (de Bondt and van den Berg 2012; Rawsthorn 2011). To make sure students can learn from a wider range of role models - who according to aspects such as gender, race, socio-economic and geographical background, will have to deal with different aspects of precarious work - we invite you to check your teaching for the following aspects: does my teaching and the organization of events include practices led by women, people of colour and any other underrepresented social group? Does it include practices based in non-western countries and in rural areas? 
Does it include practices that fall outside conventional business models? Does it include practices that challenge conventional notions of success?

\section{Making the economies of live-projects intelligible}

Within a design course, organizing live-projects, i.e. projects where students work with client organizations outside the university, can be a great way to allow students to gain a complex range of design experiences and they are even more so when these economies are made transparent. Thus, we invite design educators organizing such live-projects to experiment with how they can give students an insight into the following questions: What are the transactions between the different parties involved? If money is changing hands, how much is it? Where does it come from and what is it spent on/needed for? What else is being exchanged? Can you calculate together with the students what the full cost/value for such a project would be?

\section{Contextualizing internships and work placements}

As internships are part of many students curriculum, here is a range of questions to address together with the students when discussing that particular period of their studies:

What sort of exchange and economy is one entering into as an intern? What is problematic about unpaid and underpaid work? How to make sure internships and work placements become a valuable learning experience? How can students envisage feeding their experience back to their peers and to discuss the pros and cons of their experience? What alternatives if any, are there? 


\section{Discussing and passing on the tools of the trade}

Making a living as a designer is not just about being passionate about one's work, but also about knowing how to get paid for what one produces. Especially because there is no one way to calculate the value of design work, we think it is important to address the following questions with students: How do you negotiate conditions of exchange with the people or companies you work for (or with people that will work for you)? What does an estimate look like and what should it include? How to calculate your fee? What does an invoice look like? What kind of basic contracts can a freelancer put in place? What professional associations or unions can one be part of that lobby for the rights of freelancers and small design studios?

\section{Discussing inclusivity and exclusivity in the field of design}

Working as a designer is tied to social and material aspects such as high levels of flexibility, extensive professional networks, the availability of monetary savings, good health and enthusiasm. Having or not having them can be a key factor in how one's working life unfolds. Can we discuss these factors with students? What are the positive and negative consequences of these requirements? How do they influence who can work as a designers and make a living from it? Who is it that we are not seeing in the design press or in established positions within the design industries? What would need to change to make designers a more diverse and inclusive group of people? Why should we all care about diversity and inclusivity? 


\section{Thematizing healthy working habits}

As a matter of fact, many designers are struggling with health issues caused by overwork, screen-based and sedentary work habits (Cantiere per pratiche non-affermative 2013: 21). Can we find a space to address the main health problems designers face and support students in developing routines that help to prevent them? What are the main health problems designers face? What routines can help in preventing them? What strategies can prevent stress and overwork? What does a healthy workspace set up look like? How are issues of bad health systemically connected to the working conditions and habits of designers? How are issues of psychological pressure tied to key affects (such as happiness, entrepreneurial spirit, competitiveness) demanded by a neoliberal economy?

\section{Thematizing student debt and institutional economies}

With rising student fees - especially in the United Kingdom - debt is becoming a pressing issue for many of the people we teach, while precarious contracts are the norm for many of the people teaching. Can we - in our roles as educators, school staff and/or students - make space to address this very present yet taboo issue? What are the consequences of student debt - for the debtors, for society? How can student debt be framed in ways that go beyond individual responsibility? How are particular design schools funded? What kind of contracts are teaching staff employed on?

\section{Exploring the chains of labour designers are tied into and foster}

While it is important to tackle issues about precarious work designers face, it 
is also important to enquire what kind of labour the field of design is part of and contributing to. Who produces the computers, technological infrastructures and materials we rely on? Under what conditions and with what ecological impact are they produced? Who cleans our classrooms and provides other invisible services? What labour relations and resource extraction does the production of our projects rely on? What aspirations and social relations do our design projects foster? Where do we see points for intervention to contribute to ecologically and socially just relations?

The didactic proposals and strategic questions just laid out are either integrating or giving routes of access to more didactic tools that we have gathered on the website accompanying this practice-based research (www.precariypilot.net). The tools presented on the website follow the same approach we have taken here, where we try not to reduce the addressing of precariousness to a question of individual 'career development' but try to make it an approach of pre-figurative politics, where a desired state of affairs is enacted in the here and now. This means that what we propose is not about enquiring how individual practitioners can perform better (whether as freelancer, studio owner or in any other capacity), but about how the whole system could be transformed. For us, addressing the precarious work politics of design, is not about how one rat can win the rat race, but about how the rat race can be subverted - tweaking one teaching habit at a time.

\section{Acknowledgements}

We would like to thank all the students, recent graduates and educators that have participated in our Precarity Pilot workshops. We especially would like to thank 
the design educators and two anonymous reviewers who commented on a first draft of this text and the members of the Graphic Design Educators Network, who discussed a first draft with us during the Exploring Territories conference held in September 2016 at Cardiff School of Art and Design.

\section{References}

Berardi, F. (2009), Precarious Rhapsody: Semiocapitalism and the Pathologies of the Post-Alpha Generation, London: Minor Compositions.

Berlant, L. (2011), Cruel Optimism, Durham: Duke University Press.

Cantiere per pratiche non-affermative (2013), 'Designers' inquiry: An inquiry on the socio-economic condition of designers in Italy', http://www.pratichenonaffermative.net/inquiry/en/.

Bondt, S. de and van den Berg, M. (2012), 'A history of its own? Graphic design and feminism'.

Elzenbaumer, B. (2014), 'Designing economic cultures: Cultivating socially and politically engaged design practices against procedures of precarisation', London: Goldsmiths, University of London.

Elzenbaumer, B. and Giuliani, C. (2014), 'Designers' inquiry: Mapping the socioeconomic conditions of designers in Italy', Ephemera Theory \& Politics in Organization, 14, pp. 451-59. 
Lorey, I. (2011), 'Governmental precarization', http://eipcp.net/transversal/0811/lorey/en.

McRobbie, A. (2015), Be Creative: Making a Living in the New Culture Industries, Cambridge: Polity Press.

Montgomery, A. (2016), 'What does the design industry look like?', Design Week, 31 January, https://www.designweek.co.uk/issues/25-31-january2016/what-does-the-design-industry-look-like/. Accessed 28 December 2016.

Precarity Pilot (n.d.), 'Workshops', Precarity Pilot, http://precaritypilot.net/sample-page/. Accessed 26 December 2016.

Raunig, G., Ray, G. and Wuggenig, U. (2011), Critique of Creativity: Precarity, Subjectivity and Resistance in the 'Creative Industries', London: MayFlyBooks.

Rawsthorn, A. (2011), 'Women at the drawing board', New York Times, 6 March, http://www.nytimes.com/2011/03/07/arts/07iht-design07.html. Accessed 28 December 2016.

Standing, G. (2011), The Precariat: The New Dangerous Class, London: Bloomsbury Academic. 


\section{Contributor details}

Brave New Alps produce design projects that engage people in discussing and rethinking the politics of social and environmental issues. By combining design research methods with radical pedagogy, conflict mediation techniques and DIY making, through which project outputs are produced that combine pedagogical spaces, publications, websites, photographs, videos, guided walks, urban interventions and other public events.

Bianca Elzenbaumer is an Associate Professor at Leeds College of Art.

Fabio Franz is a Ph.D. candidate at the Sheffield School of Architecture. 